\title{
Managing Congestion by using Grey Wolf Optimization for allocating FACTS \& reducing transmission losses
}

\author{
Anubha Gautam ${ }^{1}$, Parshram Sharma ${ }^{1}$, and Yogendra Kumar² \\ ${ }^{1}$ YMCA University of Science and Technology \\ ${ }^{2} \mathrm{MANIT}$
}

May 5, 2020

\begin{abstract}
The use of heuristic methods is one of the main advances in research in general since these techniques are capable of adapting themselves to problems for which it is almost impossible to obtain a suitable mathematical model. However, its use in the context of power systems is still in its initial stage, and in this work an application has been presented for the solution of a problem related to the dynamic behaviour of the electrical networks. An effective way of solving the problem of voltage control in electrical power systems is through the injection of reactive power at strategic points in the network. We present a brief description of the problem and the most appropriate measures for its solution. It is concluded that an effective way of attacking the problem is by means of FACTS devices and particularly with the inclusion of the Static VAR Compensator (SVC) and the Thyristor Controlled Series Compensator (TCSC). Because these devices have convenient features for voltage control, in addition to being flexible and allows to incorporate tasks such as damping power oscillations. The inclusion of FACT devices in power system has been presented by using SVC and TCSC to elaborate an appropriate strategy for its implementation in real systems. The optimal sizing and location of SVC and TCSC is carried out on the basis of Grey Wolf Optimization (GWO) having an end goal of loss minimization. The proposed GWO based method validates using IEEE-30 and IEEE-57 bus systems.
\end{abstract}

\section{Hosted file}

Anubha_Paper.docx available at https://authorea.com/users/299870/articles/429506-managingcongestion-by-using-grey-wolf-optimization-for-allocating-facts-reducing-transmissionlosses 

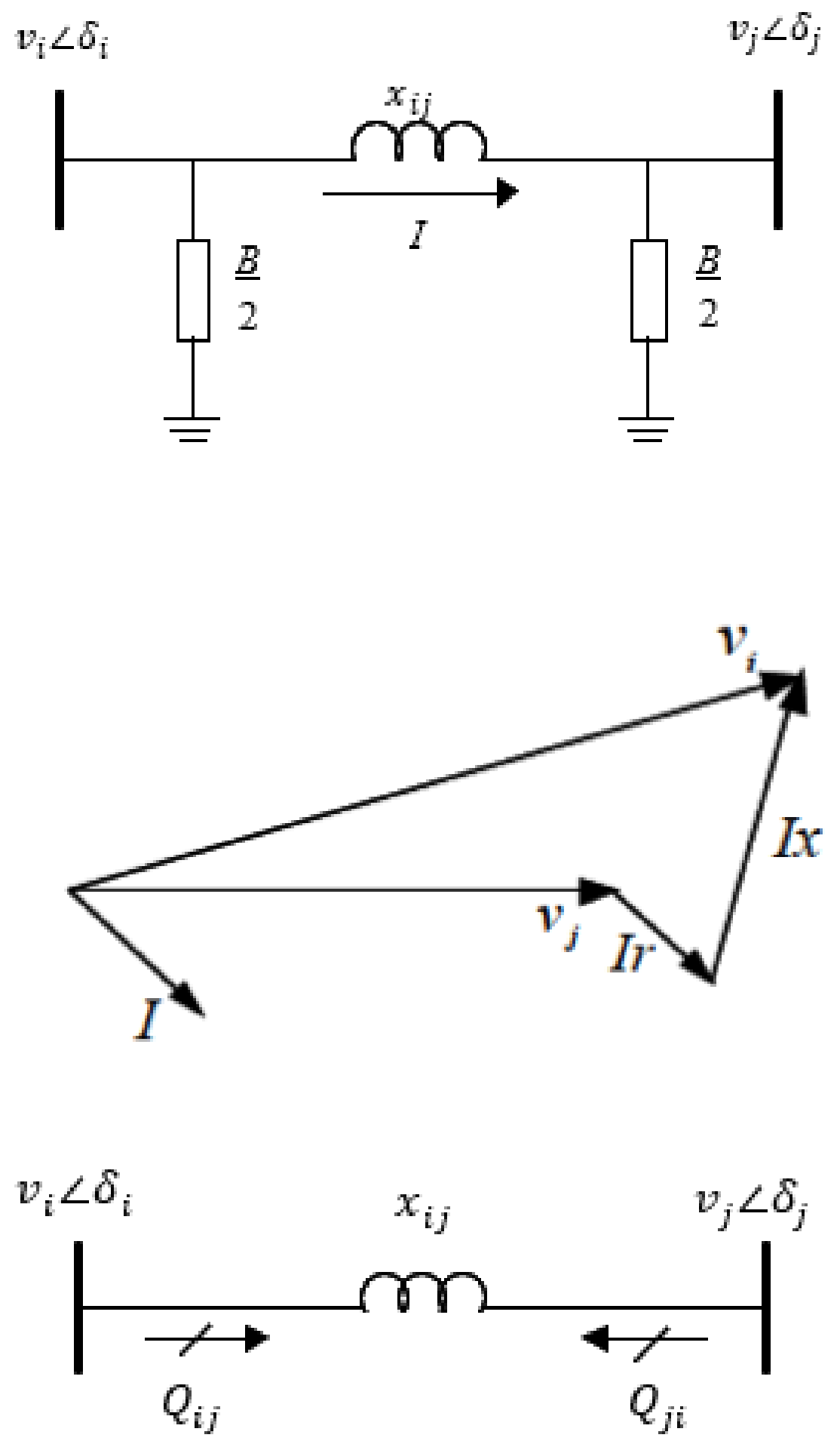

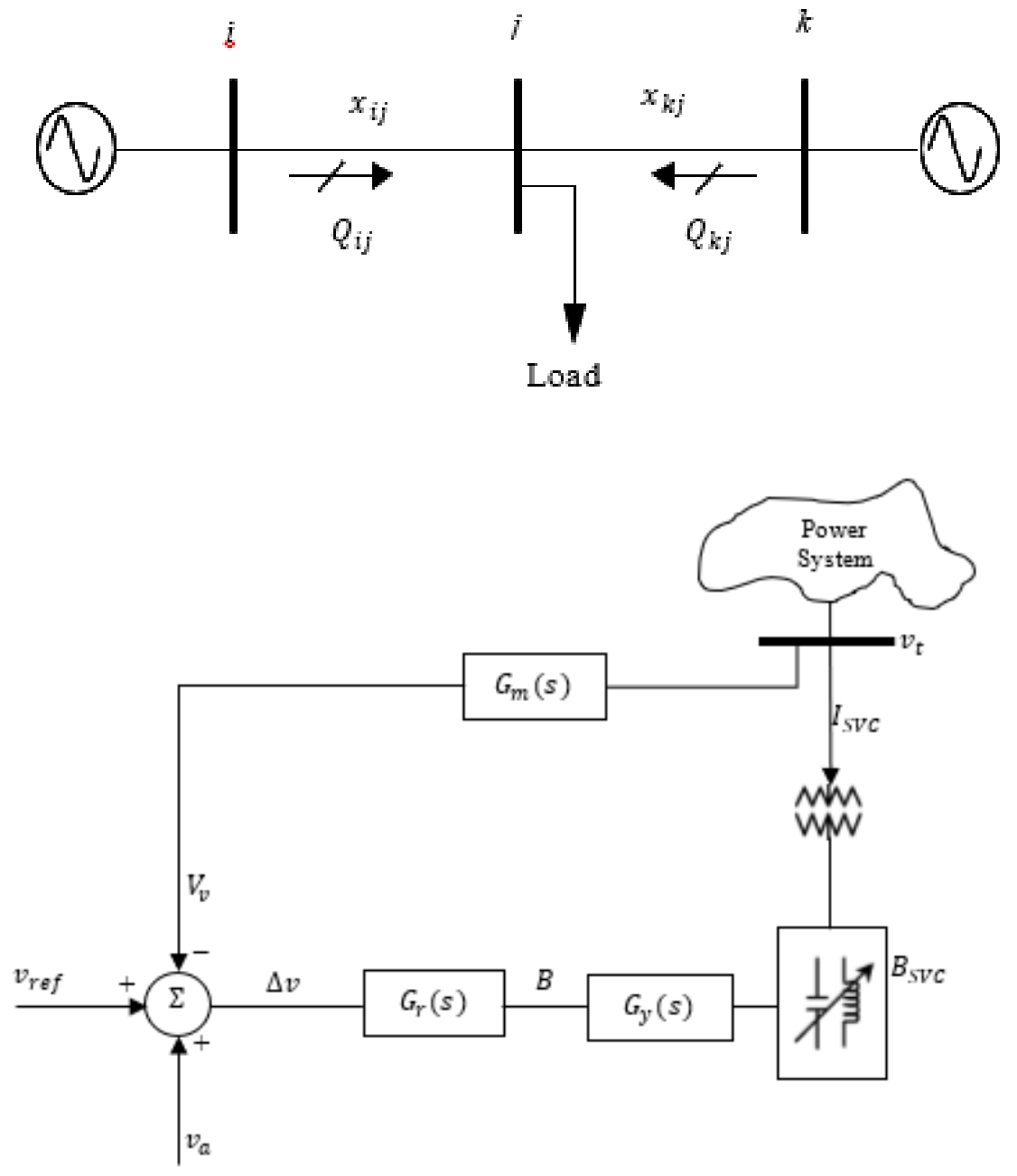

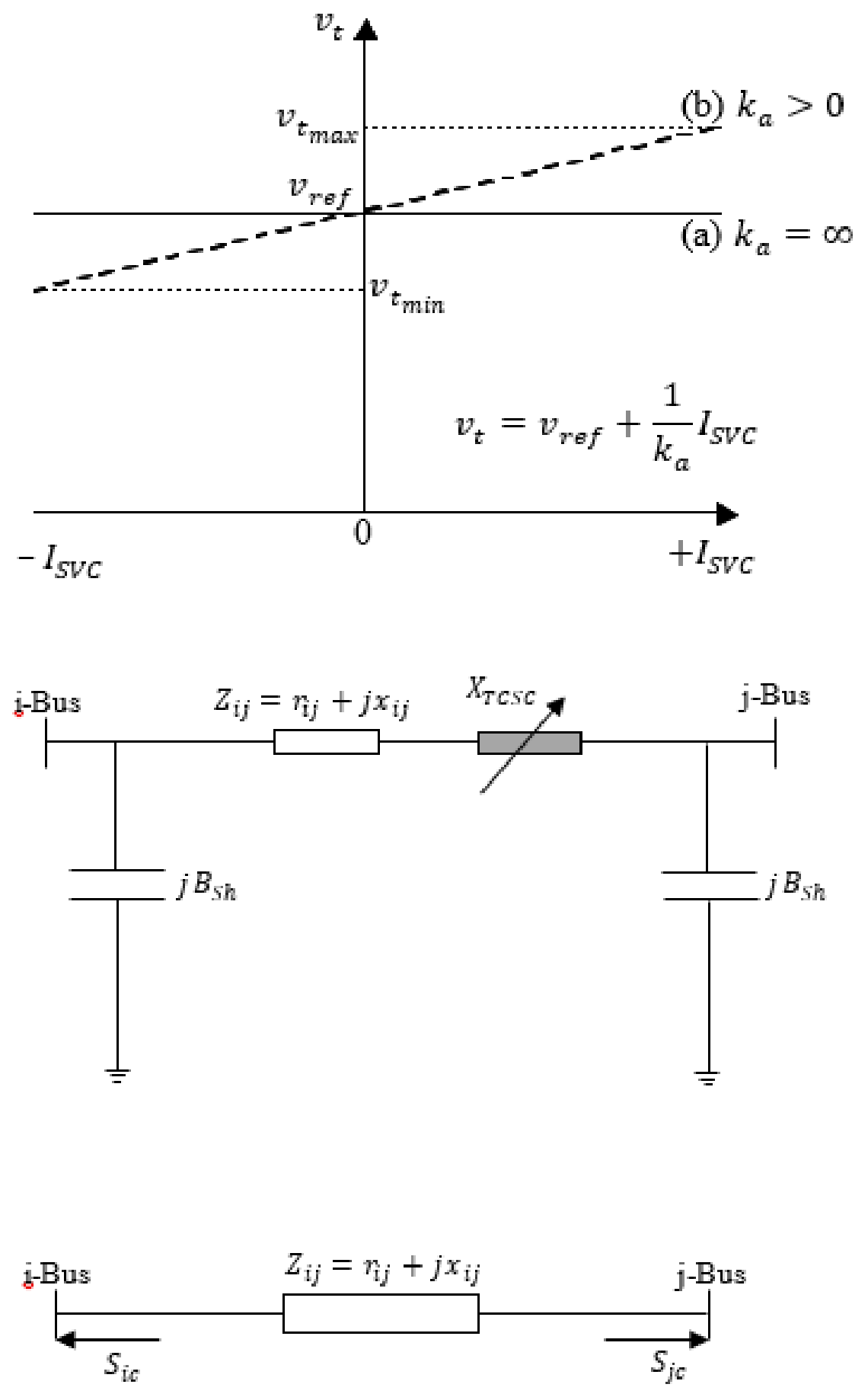

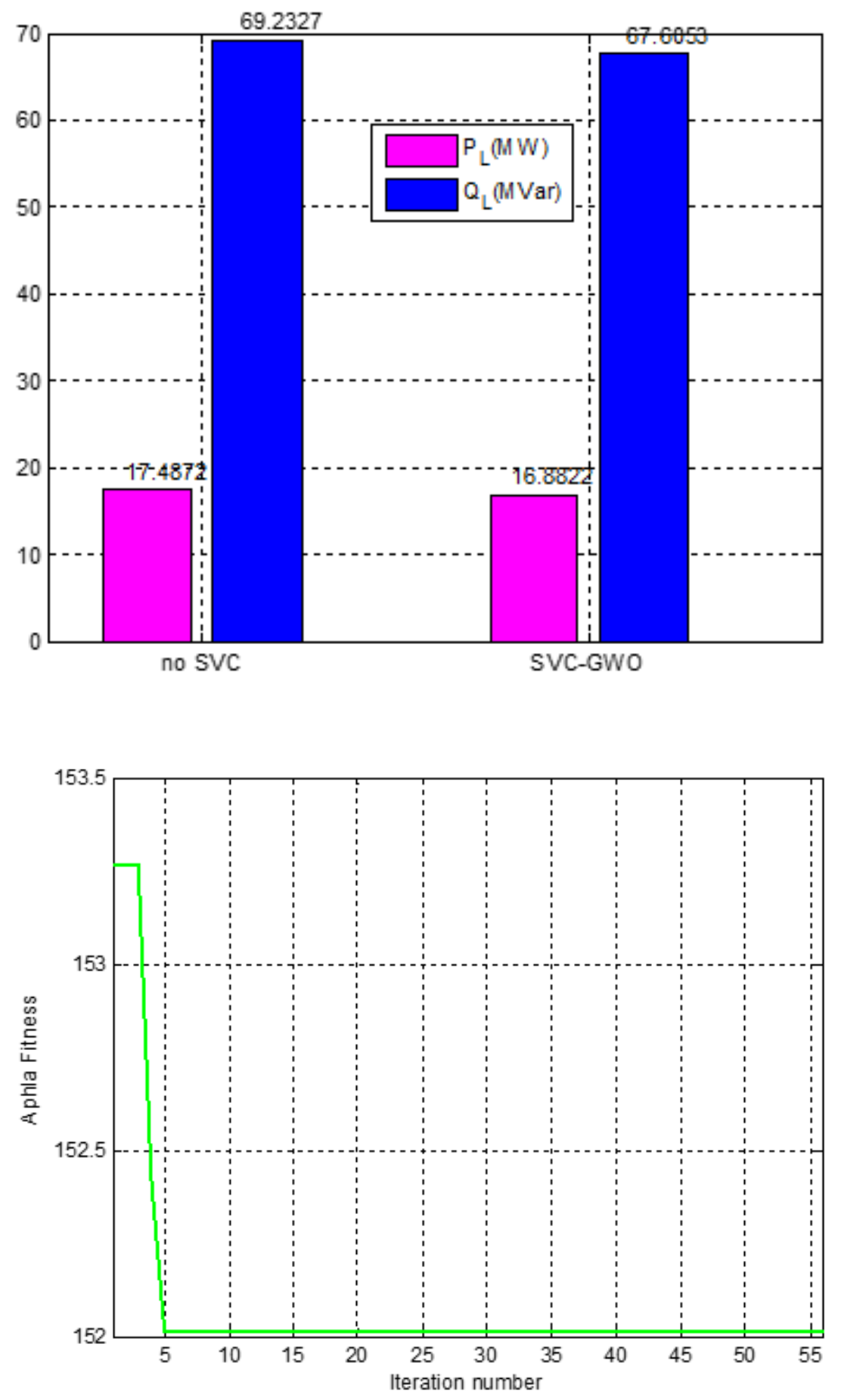

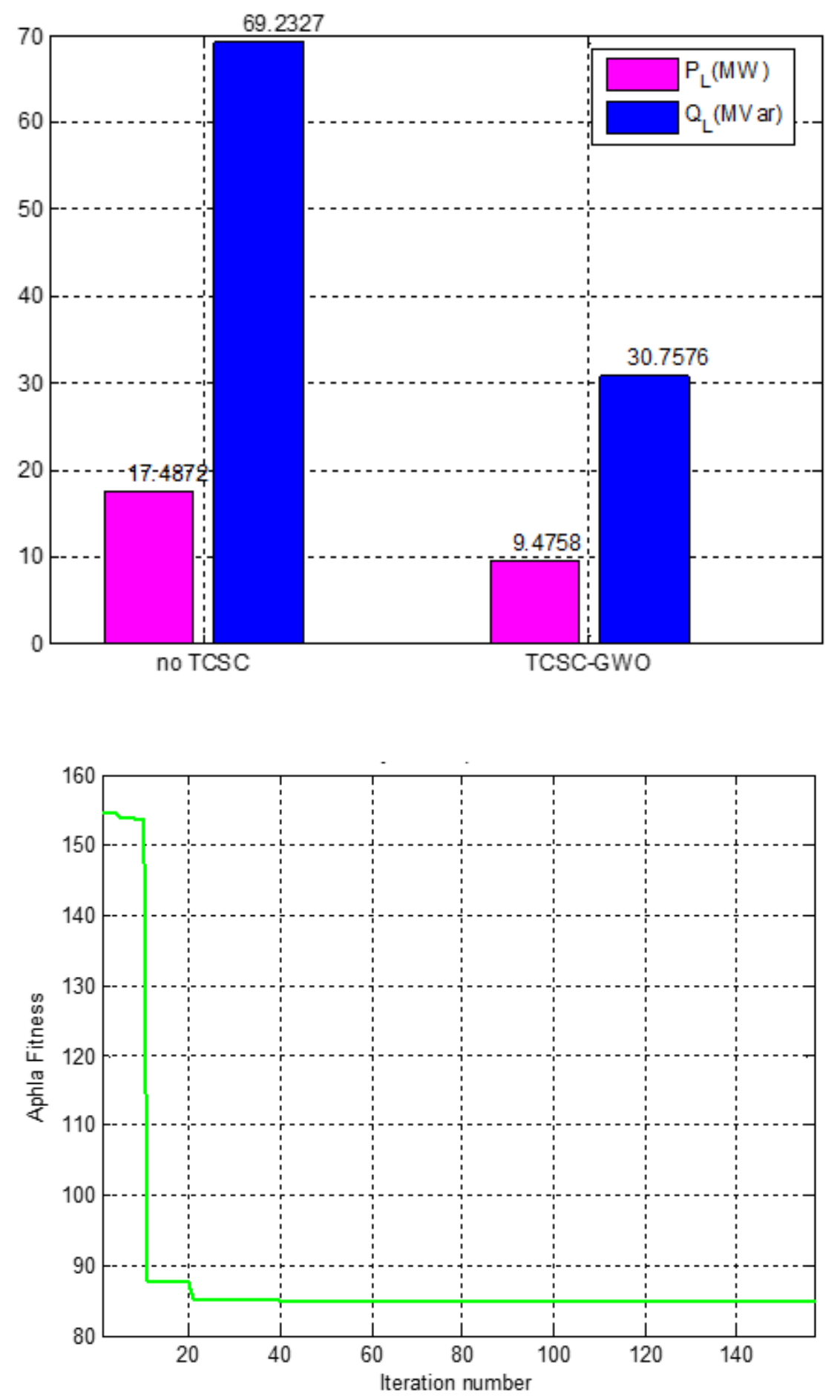

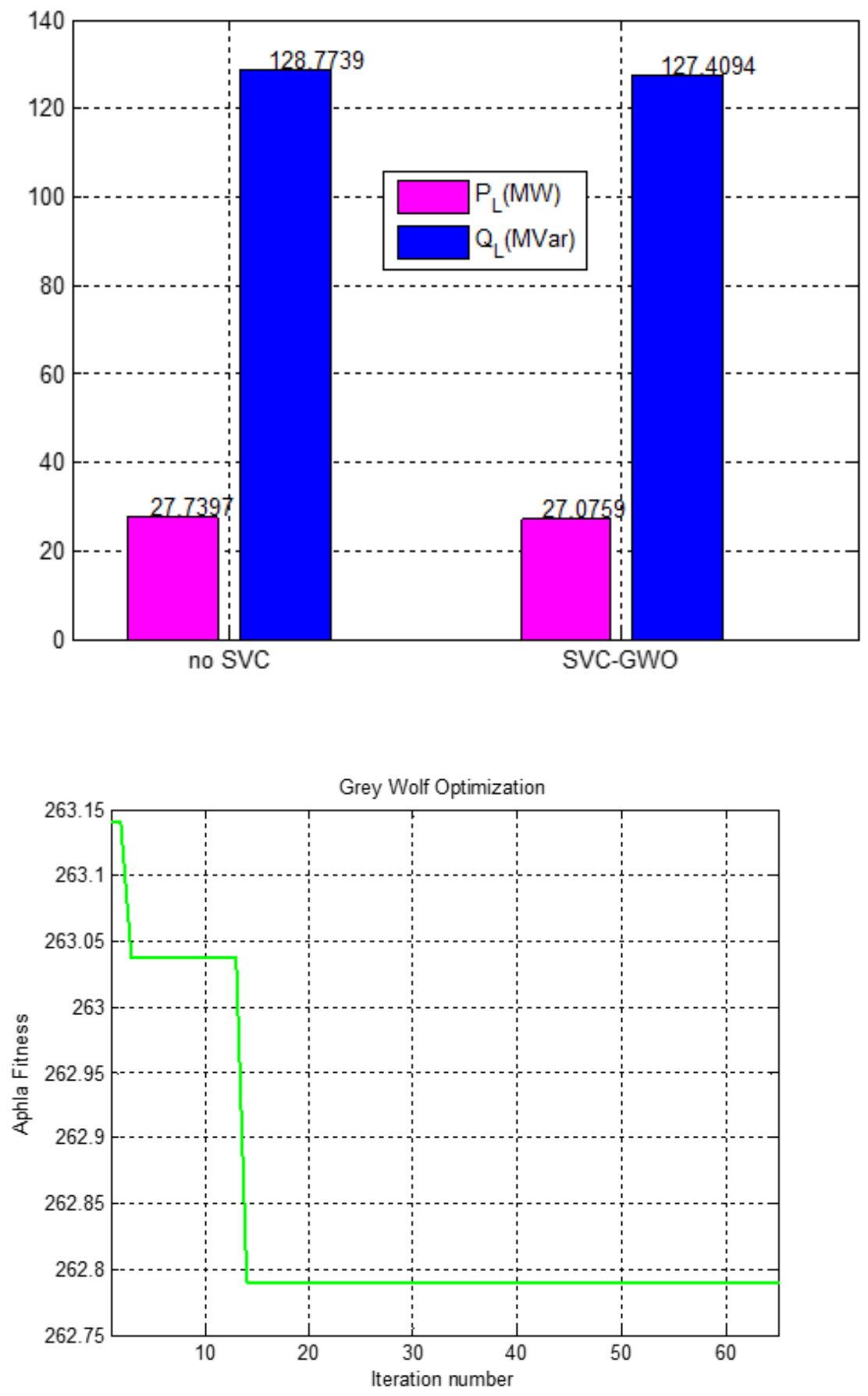

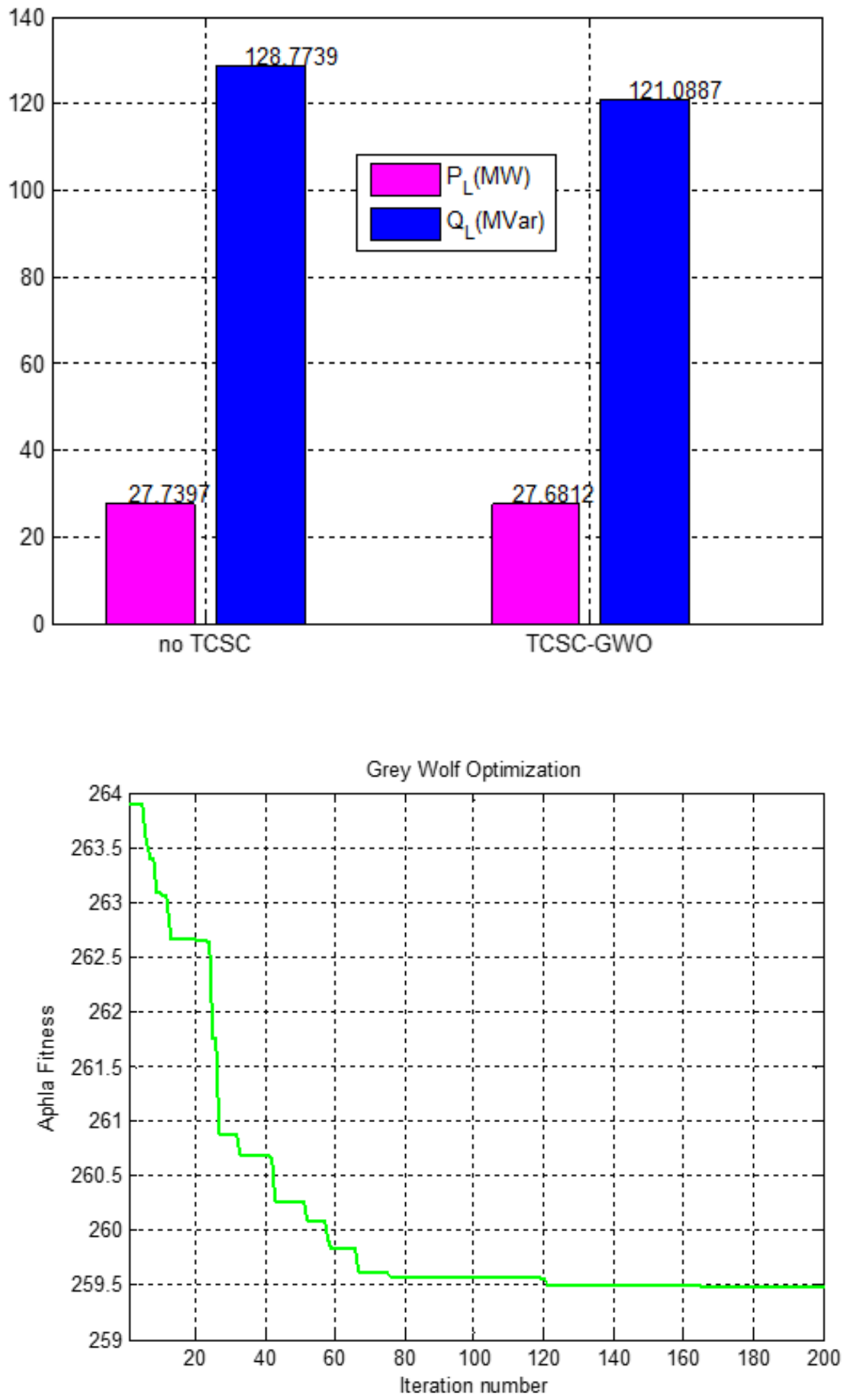

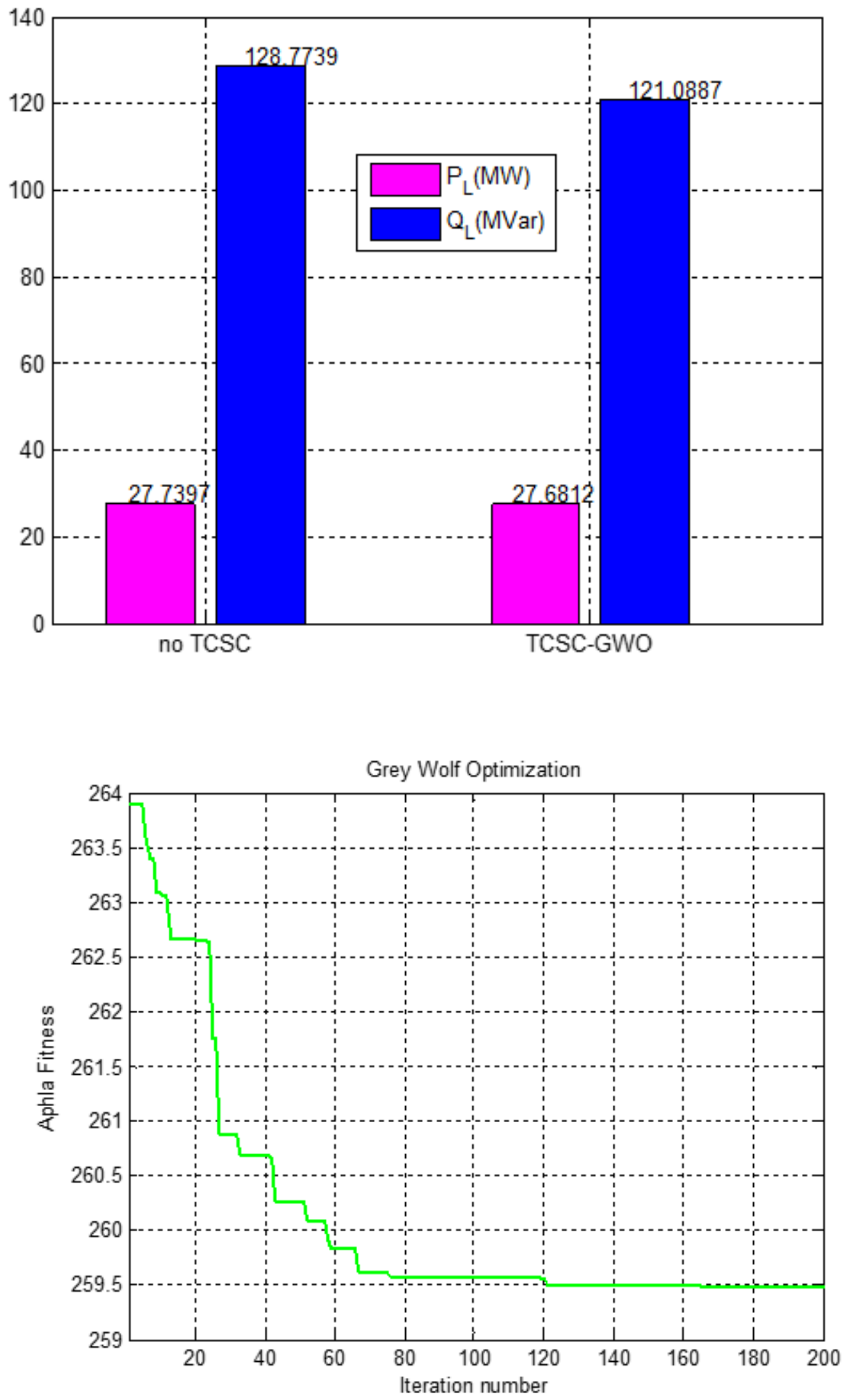